NBER WORKING PAPER SERIES

\title{
MISCONDUCT IN CREDENCE GOOD MARKETS
}

\author{
Jennifer Brown \\ Dylan B. Minor \\ Working Paper 18608 \\ http://www.nber.org/papers/w18608 \\ NATIONAL BUREAU OF ECONOMIC RESEARCH \\ 1050 Massachusetts Avenue \\ Cambridge, MA 02138 \\ December 2012
}

We thank Luciano de Castro, Tim Feddersen, Craig Garthwaite, Tom Hubbard, Bruno Jullien, Mike Mazzeo, Nicola Persico, Mike Powell, Max Schanzenbach and seminar participants at the Harvard Business School, Haas School of Business at UC-Berkeley, Kellogg School of Management, Florida State University, NYU Stern, 2012 NBER Law \& Economics Summer Institute, Center for Research in Economics and Strategy Conference, 2013 IIOC, and LMU Munich Workshop on Natural Experiments and Controlled Field Studies for helpful comments. We are grateful to Eric Zhang and Tongtong Shi for excellent research assistance. We also thank individuals at the Texas Department of Insurance for their help in acquiring the data. The views expressed herein are those of the authors and do not necessarily reflect the views of the National Bureau of Economic Research.

At least one co-author has disclosed a financial relationship of potential relevance for this research. Further information is available online at http://www.nber.org/papers/w18608.ack

NBER working papers are circulated for discussion and comment purposes. They have not been peerreviewed or been subject to the review by the NBER Board of Directors that accompanies official NBER publications.

(C) 2012 by Jennifer Brown and Dylan B. Minor. All rights reserved. Short sections of text, not to exceed two paragraphs, may be quoted without explicit permission provided that full credit, including $(\mathrm{C}$ notice, is given to the source. 
Misconduct in Credence Good Markets

Jennifer Brown and Dylan B. Minor

NBER Working Paper No. 18608

December 2012, Revised October 2013

JEL No. D8,G2,L15,M5

\begin{abstract}
Jennifer Brown
Department of Management and Strategy

Kellogg School of Management

Northwestern University

2001 Sheridan Road

Evanston, IL 60208

and NBER

jen-brown@kellogg.northwestern.edu

Dylan B. Minor

Kellogg School of Management (MEDS)

Northwestern University

2001 Sheridan Road

Evanston, Il 60208

d-minor@kellogg.northwestern.edu
\end{abstract}

ABSTRACT

We examine misconduct in credence good markets with price taking experts. We propose a market-level model in which price-taking experts extract surplus based on the value of their firm's brand and their own skill. We test the predictions of the model using sales complaint data for exclusive and independent insurance agents. We find that exclusive insurance agents working for large branded firms are more likely to be the subject of a justified sales complaint, relative to independent experts, despite doing substantially less business. In addition, more experienced experts attract more complaints per year. 
“... will people push the envelope and pitch lucrative and complicated products to clients even if they are not the simplest investments or the ones most directly aligned with the client's goals? Absolutely. Every day, in fact."

- Greg Smith, former executive at Goldman Sachs

New York Times Op-Ed (March 14, 2012)

Expert services firms often advise customers in markets with substantial asymmetric information problems; however, with these asymmetries comes the potential for expert misconduct. Specifically, while experts benefit from customers trusting their recommendations, they may also face incentives to provide misleading advice for their own gain. For example, investment or insurance advisors can recommend products that offer customers less benefit, but provide themselves with greater revenue than the customers' ideal products.

This paper explores misconduct in markets with price-taking experts. In particular, we explore differences in the incentives for misconduct for experts working exclusively for large branded firms versus those working as independent sellers. Our interest in these settings is motivated by their empirical prevalence - many financial services experts face fixed prices and commission rates while operating under one of the two prominent organizational forms. We also consider the relationship between misconduct and expert experience.

Existing studies have shown that misconduct in the financial services market is more than just a theoretical possibility. Mullainathan, Noeth, and Schoar (2012) conduct a field audit study in a U.S. market and find that financial advisors often recommend self-serving products. Anagol, Cole, and Sarkar (2012) conduct an audit study of insurance sales agents in India and find similar results. Even financial experts themselves acknowledge the ethical quandary of their field. In Cooper and Frank (2005), a survey of insurance agents finds that agents consistently identify ethical issues relating to the conflicts between customer benefits and opportunities for personal financial gain. We contribute to the discussion of misconduct in these markets by providing a stylized market-level model of misconduct that provides predictions that we can test empirically using data from life insurance sales.

While our empirical work focuses on the life insurance market, the findings may be of wider interest - financial services fall broadly into the category of credence goods. With credence goods, it is difficult for a customer to determine whether the product or service is the best match for his or her needs. Because of this, an expert who both advises and receives revenue based on his advice faces conflicting incentives. High quality advice may improve the customer's payoff; yet, when taken by the customer, inappropriate advice may lead to higher expert revenue.

In the paper, we use the simple market-level framework to consider the role of organizational form. We argue that, for a given level of malfeasance, customers working with 
exclusive agents at large firms fare better in expectation relative to customers using independent experts. Several features of our industry of interest-life insurance and annuities sales - support this notion. For example, experts working exclusively for large branded companies may offer additional services and support, experts working as representatives of large, hierarchical organizations may be more heavily monitored by supervisors, or customers may simply value working with a branded insurance expert for reasons beyond the tangible features of their service. Because the experts are price takers, those who provide larger expected consumer benefits cannot adjust their prices to extract this surplus directly; instead, the exclusive experts extract surplus through greater misconduct.

The model provides similar intuition for understanding the role of expert experience. If more experienced experts are less prone to mistakes, then their customers enjoy higher expected payoffs. In turn, however, experienced experts may try to appropriate these benefits through greater misconduct.

We test these two main predictions using data on life insurance and annuities' consumer sales complaints. Although complaints are an imperfect measure of misconduct, complaints data summarizing accusations investigated by a state insurance regulator offer us a window into actual misconduct and allow us to explore the impact of different organizational structures on expert behavior. In general, studies of misconduct face a trade-off: direct observation of misconduct through field experiments is necessarily limited in scale, while administrative data on reported misconduct may suffer from selection biases. In this paper, we use data on misconduct that has been reported to and investigated by a state regulator. Thus, we can take advantage of the observation of both accusations of misconduct and confirmed cases to consider the role of reporting and selection biases. We match life insurance licensing data with company affiliations and detailed sales practice complaint records from the Texas Department of Insurance. From company affiliation data, we identify two types of experts: agents who work exclusively for large, branded companies and agents who work independently.

Our findings are consistent with the predictions of the market-level model. Specifically, we find that exclusive agents face more justified complaints than independent agents, despite enjoying lower market share. We also find that more experienced agents have greater per year complaint rates than less experienced agents.

The information asymmetries in our theoretical and empirical settings cannot be fully resolved through reputation building. Indeed, the nature of credence good markets means that misconduct is seldom observed; therefore, the signals required for reputation building on this dimension are not sufficiently informative (Mailath and Samuelson 2001). As a result, it is not possible to build a reputation explicitly for ethical behavior. Curiously, 
we still observe strong branding by firms in many credence good settings - for example, insurance companies, wirehouses, and hospital networks are often heavily advertised. Our results provide an interesting counter to the conventional view of brand. While branding and reputation solve informational asymmetry in many markets, in our empirical setting, the correlation between strong branding and higher additional surplus leads to the prediction that experts from large, branded firms are actually more likely to engage in misconduct.

\section{Related Literature}

Our work contributes to the literature on credence goods, established by Darby and Karni (1973). Much of the work that followed modeled experts who could adjust both quality and price. In contrast, we explore a credence good market with price-taking experts. Pitchik and Schotter (1987) isolate the problem of the expert honestly suggesting a mode of treatment and provide comparative statics results comparing price and quality controls and the level of honesty. Pessendorfer and Wolinsky (2003) study the first stage of a similar problem: the need to provide incentives for the expert to expend enough effort to identify and provide a correct solution. Sulzle and Wambach (2005) explore how changing physician and patient incentives through higher coinsurance levels may (or may not) induce patients to increase physician search and encourage physicians to reduce fraud. Alger and Salanie (2006) also consider the role of the client and find that a patient's ability to reject an expert's recommendation creates a market failure. Emons (1997) shows that market equilibria with honest expert behavior exist when customers can infer sellers' incentives for fraud from market data. Gennaioli, Shleifer, and Vishny (2012) study the behavior and market outcomes of trusted investment managers when investors' beliefs are misguided.

The literature has also carefully considered the importance of customer heterogeneity. Fong (2005) shows that cheating arises when firms target high-valuation and high-cost customers. Feddersen and Gilligan (2001) find that third parties, namely activists, can ameliorate the credence good problem. Taylor (1995) examines multi-period contracts and warranties as another solution. Inderst and Ottaviani (2009, 2012a, 2012b) study firms trying to induce agents to provide advice to imperfectly informed customers. They find that misselling depends on firm asymmetries, customer awareness, and agents' utility from giving suitable recommendations. Broadly, in their models, agents provide honest advice when firms are symmetric or there are sufficiently many aware customers in the market. Lightle (2009) considers the opposing case where an expert attempts to maximize his customer's payoff. Dulleck and Kerschbamer (2006) present a model that unifies the extant literature and rationalizes many of the previous theoretical findings. Our work complements these studies by adapting our market-level model of price-taking experts to explore the role of customer heterogeneity. 
Despite the challenges, several empirical studies have examined experts decisions about what quality to provide and what price to charge their relatively uninformed customers. Hubbard (1998) explores empirically the incentives faced by experts in automotive repair services. He finds that private firms are more likely than state inspectors to help vehicles pass emissions tests. Moreover, he finds that independent experts are more likely to provide favorable inspection reports, relative to branded "chain" shops with non-owner managers. Hubbard (2002) suggests that the possibility of many future transactions provides incentives for experts to offer more favorable advice, particularly where experts are residual claimants. Free-riding may also dampen individual experts' incentives, as firms with more inspectors tend to help vehicles pass less frequently. Levitt and Syverson (2008) find that real estate agents invest more effort and secure a higher price for the sale of their own property, relative to their customers' homes. Similar to the mechanism proposed by Hubbard (2002), Levitt and Syverson argue that the absence of frequent and repeated interactions limits customers' abilities to verify their agents' service quality. They also find that the difference between agent-owned and non-agent-owned sale prices is increasing in the degree of asymmetric information about property values.

We build on these empirical papers by exploring another important industry setting in which, unlike with vehicle inspectors and real-estate agents, experts face rigid commission rates. While we focus on life insurance sales, other examples of price-taking experts include physicians with limited scope to adjust prices for specific patients and experts facing formally regulated prices.

The paper proceeds as follows. In the next section, we propose a market-wide model of expert misconduct that considers the role of both organizational form and expert experience. In Section 2, we provide an overview of some important institutional features of the insurance industry. In sections 3 and 4 , we describe our data and provide evidence of a difference between the complaints against exclusive and independent insurance salespeople. In section 5 , we consider several alternative explanations for the empirical findings. The final section discusses how our findings relate to policies proposed after the recent financial crisis.

\section{A model of price-taking experts}

In this section, we present a market-level model of consumers and experts. The model is inspired by the unifying model in Dulleck and Kerschbamer (2006), hereafter DK; however, we adapt the framework to consider price-taking experts. In DK, different outcomes are driven by experts offering services at different prices (e.g. mechanics choose quality and prices for auto repairs). In fact, virtually all of the aforementioned theory papers studied 
price-setting firms or advisors.

We develop the model to generate predictions about two dimensions of many expert services markets. First, we aim to understand if and how market-level misconduct varies across two common organizational forms - in particular, we compare misconduct from experts who work exclusively for large companies and independent experts who form their own small firms. Second, we consider how misconduct varies across experts with different levels of experience.

Our model is stylized, allowing us to focus on the two dimensions of interest. In Section 2, we explore one particular empirical setting and map the details of that industry to the following theory.

\subsection{Model set-up}

Consider an interaction between an expert and a customer that can result in two outcomes: the expert can recommend either an appropriate or inappropriate product. For convenience, we will use the index " $R$ " and " $W$ " as mnemonics for the "right" and "wrong" products, respectively. We assume that the expert knows which product is appropriate for the customer, but the customer does not. After the expert makes his product recommendation, the customer must chose to buy or not to buy.

Suppose that $\pi^{R}$ and $\pi^{W}$ are the payoffs to an expert for selling the appropriate and inappropriate products, respectively. Payoff $\pi^{t}$ is a reduced form representation of the net payoff (i.e., gross revenue minus business expenses) of selling product $t \in\{R, W\}$, before any possible penalty for mis-selling to a customer (i.e., recommending $W$ ).

As depicted below, the timeline for the expert-customer interaction is sequential.

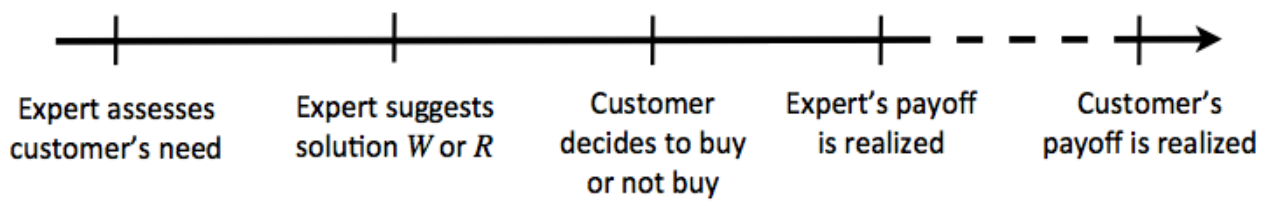

An expert's private cost of misconduct, penalty $k$, can be framed as his willingness to take advantage of a customer. Let $k$ be drawn from a commonly known distribution $F(\cdot)$. In equilibrium, there is some chance $b$ that the expert will face a customer who will act on his recommendation. Thus, taking $b$ as given, the probability that any given expert suggests $W$ to a customer is

$$
\left.\left.\left.\operatorname{Pr} b \pi^{W} \square k \geq b \pi^{R}\right)=F \quad b \quad \pi^{W} \square \pi^{R}\right)\right) \equiv s(b)
$$

where $s(b)$ is the market-wide misconduct rate. To allow for the possibility of misconduct, 
we assume $F(0)=0$.

Now suppose that the customer earns a net payoff of $V^{R}$ from buying $R$ and $V^{W}$ from buying $W$, where $V^{W}<0<V^{R}$. If the customer decides not to buy the product, then her payoff is 0 (her normalized outside option). Hence, a customer will buy if

$$
s V^{W}+(1 \square s) V^{R} \geq 0 .
$$

We define a customer's payoff ratio as $\frac{V^{R}}{\square V^{W}}$ (recall that $V^{W}<0$ ), which is distributed according to $G(\cdot)$. Hence, the probability that a particular customer buys is

$$
\begin{aligned}
\left.\operatorname{Pr} s V^{W}+(1 \square s) V^{R} \geq 0\right) & =\operatorname{Pr}\left(\frac{V^{R}}{\square V^{W}} \geq \frac{s}{(1 \square s)}\right) \\
& \Longrightarrow 1 \square G\left(\frac{s}{(1 \square s)}\right) \equiv b(s)
\end{aligned}
$$

where $b(s)$ is the market-wide buy rate.

To find the market equilibrium, we find the fixed point such that $s(b(s))=s$.

\subsection{Exclusive vs. independent experts}

We first enrich the model by considering two different organizational structures: experts may work exclusively for a large companies or as independent experts who form their own small firms. We index these experts with $m \in\{E, I\}$.

We assume that the price-taking experts face similar payoffs across organizational forms $\left(\pi^{t}=\pi_{I}^{t}=\pi_{E}^{t}\right)$ and the payoffs to customers vary across firm types - this is consistent with features of our empirical setting. In particular, customers gain additional payoff from working with a branded firm using exclusive experts.

To capture the wedge between customers' payoffs from different organization forms, we assume that $\frac{V_{E}^{R}}{\square V_{E}^{W}}=\frac{V_{I}^{R}}{\square V_{I}^{W}} \eta>\frac{V_{I}^{R}}{\square V_{I}^{W}}$, where $\eta>1$. With this parameterization, the probability that a customer purchases from an exclusive expert is

$$
1 \square G_{E}\left(\frac{s}{\eta(1 \square s)}\right) \equiv b_{E}(s)
$$

and the probability that a customer purchases from an independent expert is

$$
1 \square G_{I}\left(\frac{s}{(1 \square s)}\right) \equiv b_{I}(s)
$$

This parameterization can be motivated by assuming customers have some valuation of 
brand in addition to the intrinsic product features. In a survey on brand equity, Keller and Lehmann (2006) note that while brand can communicate tangible aspects of a product or service, a brand can also represent important intangible attributes that differentiate those goods. According to the authors, these attributes "transcend physical products" and may be supported by both words and images. These intangibles can create positive associations between the good and the company that produces it - further, this value need not be based on objective usage experience. Cobb-Walgren et al. (1995) compare goods that have virtually identical objective values, but differ in terms of brand equity. They find that the good with greater brand equity is associated with more positive features and fewer negative features, relative to the good with a weaker brand. In short, successful branding can prompt customers to value a good beyond its objective, tangible value.

Beyond brand, it could be that customers particularly value some exclusive products available only through the branded firm. Other features that can support the disparity between the value offered by the two organizational forms include differences in the breadth of services offered, multi-product discounts, online account access, 1-800 telephone support, or multiple service locations that large, branded firms offer. Finally, it could also be that customers take comfort in working with an expert who is placed in an organizational structure with a branch manager charged with overseeing expert conduct. That is, the possibility and severity of misconduct for a given level of attempted misconduct may be lessened in working with such a branded organization.

With these preliminaries, we can now describe market-wide outcomes for exclusive and independent experts. The market-wide equilibria can most easily be identified through a graphical analysis. A formal proof, along with additional intuition, is available in the Appendix. In Figure 1, we plot expert misconduct against customer buy rates. As expected, buy rates are decreasing functions of the market-wide misconduct. Specifically, the solid downward sloping line, $b_{I}(s)$, plots the buy rate for customers of independent experts. The dotted line, $b_{E}(s)$, plots the buy rate for customers of exclusive experts. For all interior points, $b_{E}(s)$ lies above $b_{I}(s)$. Intuitively, for a given level of market-wide misconduct, customers will buy at a higher rate from exclusive experts because, in expectation, they receive a higher expected payoff. The upward sloping line, $s(b)^{\square 1}$, is the inverse of the market-wide misconduct rate. It slopes up because there is more market-wide misconduct when customers are more likely to purchase - more experts will find it profitable to take advantage of customers when customers are keen to purchase. The intersections of these curves identify the equilibria and lead to our first prediction in Proposition 1.

Proposition 1 Exclusive experts are more likely to engage in misconduct than independent experts: $s_{E}^{*}\left(b^{*}\right)>s_{I}^{*}\left(b^{*}\right)$. 
Proof. See Appendix.

\subsection{Observable Differences in Expert Skill}

In this section, we consider the effect of experts' skill differences on market-wide misconduct. Consider a version of the model where, on occasion, experts inadvertently recommend the inappropriate product. Thus, we assume that an expert makes harmful mistakes. ${ }^{1}$ As we detail in Section 2.2, in practice, regulators often view intentional and unintentional actions differently - unintentional mistakes are not considered misconduct. Of course, the expert is also able to choose to recommend the inappropriate product, since that may increase his revenue at the customer's expense. These acts are considered professional misconduct by the regulator.

Let $h$ be the commonly known probability that an expert makes an error. Now, the probability that a particular customer buys is

$$
\begin{aligned}
\left.\operatorname{Pr}\left[s V^{W}+(1 \square s)(1 \square h) V^{R}+h V^{W}\right) \geq 0\right] & =G_{h}\left(\frac{s+(1 \square s) h}{(1 \square s)(1 \square h)}\right) \\
& \Longrightarrow 1 \square G_{h}\left(\frac{s+(1 \square s) h}{(1 \square s)(1 \square h)}\right) \equiv b_{h}(s)
\end{aligned}
$$

We describe the market-wide consequence of error-prone experts in Figure 2. Let $a$ be experts' error rate. The customer buy rate from experts who makes errors, presented as the downward-sloping solid line $b_{h=a}(s)$, lies above the buy rate for experts with an error rate greater than $a$, shown as the downward-sloping dotted line $b_{h>a}(s)$. All else equal, a customer is less likely to buy from a more error-prone expert. Consequently, in equilibrium, experts with lower error rates engage in more misconduct, as can be seen in Figure 2. We summarize this finding in our next proposition:

Proposition 2 More error-prone experts are less likely to engage in misconduct. That is, $s^{*}$ is decreasing in the error rate $h$.

Proof. See Appendix.

Corollary 3 If the error rate is negatively correlated with experience, more experienced experts engage in more misconduct.

\footnotetext{
${ }^{1}$ For simplicity, we assume that experts cannot intend to recommend $W$ and mistakenly recommend $R$.
} 


\section{Life insurance: Industry background}

The model above generates two predictions about markets with price-taking experts: exclusive experts are more likely to engage in misconduct than independent experts and more experienced experts are more likely to engage in misconduct. We take these predictions to data from the life insurance and annuities market. This empirical setting is appealing on several dimensions: the industry is economically important, there exist information asymmetries between experts and customers, agents operate under two different organizational forms, and sales agents are price-takers. Moreover, data on experts and observed agent-level misconduct are available from the regulator.

The life insurance and annuities (LA) sales experience fits into the broad category of credence goods. Products are complicated and multidimensional, and it is very difficult for even sophisticated consumers to identify the appropriate product for their needs. Insurers offer multiple "riders" and introduce modifications to policies that may be opaque to customers. For example, life insurance policies can be term, universal, whole, variable and variable universal, with terminal illness and disability waivers, long-term care provisions, and accidental death benefits. ${ }^{2}$ Consequently, a customer may be sold an inappropriate product, but may never become aware of the seller's misconduct or mistake. The customer will never experience how well the life insurance policy serves his expected needs. Moreover, the insured customer and his beneficiaries may never learn whether there existed a superior product in the market at the time of purchase.

Insurance agents cannot adjust the prices faced by individual customers - this practice called "rebating" is illegal in most jurisdictions. ${ }^{3}$ Instead, an insurance agent can enhance his commissions by recommending the wrong product to a customer. This increased revenue can come from simply "overselling" the level of insurance or riders, or from selling a product with a higher commission rate and lower benefits to the buyer.

Commission rates vary significantly across and within product types. For example, commissions from annuities typically range between 2 and $10 \%$ of the invested amount. ${ }^{4}$ Typically, commissions are not disclosed to customers. In general, the tradeoff between the benefits to the policyholder and the revenue for the seller is substantial. For example, a so-called "bonus" annuity pays the customer an additional interest rate in the first year;

\footnotetext{
${ }^{2}$ The National Association of Insurance Commissions publishes a buyers' guide that describes some of the product complexities (http://www.naic.org/documents/consumer_guide_life.pdf).

${ }^{3}$ Importantly, rebating is illegal in our data environment (Texas Insurance Code Chapter 1806, Section $53)$.

${ }^{4}$ Our commission rate estimates and discussion of monitoring within firms are based on personal communication with professional insurance agents working as both exclusive and independent sellers (see Section 2.1 for a description of these organizational forms).
} 
however, the bonus rate and the commission rate are negatively correlated.

\subsection{Organizational forms}

Life insurance salespeople work primarily under the two different organizational structures considered in Section 1: (1) sellers may work exclusively for large, branded insurance companies; or (2) sellers may work as independent experts who are not affiliated with any single insurance company.

\section{Exclusive agents}

Exclusive company agents are typically affiliated with only one insurance company and may market only approved products from that company. ${ }^{5}$ In practice, these product lists are quite large, and there is little concern that exclusive agents are too constrained. Insurance companies using this organizational form may offer employment benefits packages and provide introductory training to inexperienced agents. In many cases, new agents receive guaranteed salaries that phase out as they build up "books" of business, typically over 12 to 24 months.

Multiple exclusive agents in a city or region often share the same office space and administrative staff. Hierarchy within these offices provides some level of supervision - for example, branch managers may oversee and approve large or complicated transactions.

Exclusive agents may earn 50 to $70 \%$ of the gross commissions of their sales, depending on the type of insurance product. State Farm, Farmers Insurance, Allstate, Northwestern Mutual and New York Life are examples of firms using the exclusive agent model (A.M. Best 2011); in general, these firms have well-known, easily-recognized brand names. ${ }^{6}$ We include a list of insurance companies using exclusive agents in the Appendix.

\section{Independent agents}

Independent agents are not affiliated with a single insurance company. While independent agents are not restricted to selling insurance from any particular company, they usually cannot market products from insurance companies that use exclusive agents - for example, an independent agent cannot sell any State Farm products.

Independent agents are often "one agent shops," and their transactions are not overseen by managers or supervisors. Typically, independent agents are responsible for all of their expenses; however, they generally earn close to $100 \%$ of the gross commissions on their sales. After accounting for business expenses, both company and independent agents earn roughly

\footnotetext{
${ }^{5}$ These agents may also be authorized to market selected products from other companies through agreements between their primary company and other firms.

${ }^{6}$ In 2010, State Farm, AXA, Allstate and Metropolitan Life appeared in Brandz's report on the top eight most valuable global brands in the insurance industry (report available online at http://c1547732.cdn.cloudfiles.rackspacecloud.com/BrandZ_Top100_2010.pdf).
} 
the same net commissions (Carson et al. 2007), consistent with the assumption in the theory in Section 1.

\subsection{Misconduct}

Both exclusive and independent agents can engage in various types of misconduct. In this paper, we focus on sales-level misconduct over which individual agents have control. Note that we are not considering misconduct by the insurance company, such as the unfair denial of claims.

Sales misconduct can take many forms. For example, agents can pocket the policy premium and provide the customer with fraudulent insurance documents ("conversion"). Misleading advertising about policy features and the misrepresentation of insurance-related information by an agent are also considered misconduct.

Since the bulk of total commissions for many products is earned in the first year of the life insurance policy, agents benefit from frequent policy changes. "Churning" describes the case where the agent induces a customer to (unnecessarily) cash out his existing policy in order to purchase a new policy from the same insurance company. "Twisting" is similar in nature, but involves an unnecessary switch to a new policy from a different insurance company.

Agents may also offer unauthorized rewards - in the form of payments, favors, or advantages to induce a client to purchase a new policy or product. Agents may illegally bundle products by refusing to sell or renew a customer's policy unless the client agrees to purchase additional line of coverage (e.g. life insurance tied to home or auto insurance).

These examples of misconduct are not exhaustive: Unauthorized acts and other agentlevel mishandling are other broad categories of agent-level misconduct. The second column of Table 1 summarizes common categories of misconduct and complaints.

\section{Liability}

Under U.S. law, insurance advisors are legally bound by "duty of care" and "duty of loyalty"; the former requires the agent to recommend an appropriate product for the client and the latter restricts the agent from enriching himself at the expense of his client. Under these duties, an advisor holds greater liability in the case of an intentional mistake, relative to the case in which he inadvertently offered his client a sub-optimal product. Under the "best effort" rule, advisors who present themselves as more experienced may also be hold to a higher standard. ${ }^{7}$

\section{Misconduct and Complaints}

The Texas Department of Insurance (TDI) regulates insurance-related business in the

\footnotetext{
${ }^{7}$ For an illustrative legal case, see Bloor v. Falstaff Brewing Corp., 601. F.2d 614 (2d Cir. 1979).
} 
state, including life insurance and annuities sales. Among its many duties, the TDI is charged with enforcing state insurance laws and ensuring the fair treatment of consumers. ${ }^{8}$

Complaints against insurance agents, agencies and companies can be filed with the TDI through a web-based form or by mail, fax, or email. ${ }^{9}$ Complainants are asked for detailed information about their policies, the individuals or companies involved in the complaint, and the nature of the complaint. While some of the complaint detail is considered public record, information that is protected by state and federal law remains confidential (e.g. medical records and financial information).

Upon receipt of a complaint, the TDI notifies the subject of the complaint and requests a detailed response. With that response, the TDI determines whether the individual agent or insurance company violated the terms of the contract or broke state insurance law. If the complaint is deemed justified, the TDI can levy penalties as outlined in the state insurance code.

State insurance code (Texas Insurance Code, Title 13, Chapter 4005, Section 101) requires intentionality in violations of the law-indeed, the code states that willful violations of insurance law will be disciplined. The word "knowingly" is used throughout the code to describe actions that are subject to penalty. For example, regarding the misrepresentation of policy terms, the code states that it is "...an unfair or deceptive act or practice in the business of insurance to knowingly permit the making of, offer to make, or make a life insurance contract... other than as plainly expressed in the issued contract..."

Thus, the TDI considers the intentions of agents who have acted against the interests of their customers - unintentional errors are not generally considered justified sales complaints, while intentional misrepresentation or mistreatment leads to justified complaints. This distinction is important in terms of the empirical prediction based on the propositions above, since we assume that justified complaints reflect misconduct.

\section{Data}

Our Texas insurance dataset was compiled from multiple public sources and consists of licensing, appointment, complaint, and market share information. Broadly, the data cover the population of agents operating in the state and characterize both firm affiliations and reported incidents of misconduct in Texas's insurance industry.

\footnotetext{
${ }^{8} \mathrm{~A}$ complete version of the code is available at http://www.statutes.legis.state.tx.us under "Insurance code."

${ }^{9}$ Telephone conversations with representatives at the TDI suggest that most complaints come from individual customers.
} 


\subsection{Agents}

The licensing data were acquired from the TDI and cover all agents who were licensed to sell insurance in the state of Texas in 2010. Overall, the data describe 174,792 agents licensed to sell LA. The licensing data include unique agent identifiers and the date on which each agent was first licensed in the state.

To identify the organizational form under which individual agents operate, we match company and appointments data from two sources. Company-level data were acquired from A.M. Best (2011) and allow us to identify insurance companies that use exclusive agents and those that sell through independent agents. ${ }^{10}$ We then obtained appointments data from the TDI for firms employing exclusive sales agents. Appointments data list all agents designated to sell a firm's products. Using agents' license numbers, we match license holders to firms and, thus, characterize individual agents' affiliations. Through this process, we identify 56,314 individuals who work as exclusive agents ( $32 \%$ of licensees in the state); we assume that the balance, 118,478 individuals, work as independent agents.

We also acquired marketshare data from the TDI describing the in-state total premiums written for all insurance companies operating in Texas. Table 3 reports premium and marketshare statistics separately for companies using exclusive and independent agents in Texas. Firms using independent agents hold the majority of the marketshare in LA. ${ }^{11}$

\subsection{Complaints}

The TDI maintains a public directory of complaints against insurance companies, agents and agencies. We accessed data describing more than 500,000 complaints filed between 1996 and 2010. The directory reports the date and nature of the complaint, the line of coverage, the license number of the subjects of the complaint, and whether the complaint was deemed "justified" or "unjustified" by the TDI.

Complaints vary considerably, from claims disputes to accusations about unfair cancellations. Many complaints, even those leveled at agents, relate to actions under the control of insurance companies (e.g., denial of claims and premium-related complaints).

To focus on misconduct in the sales of products with strong "credence" qualities, we narrow our analysis to the subset of complaints relating to individual agents' sales practices

\footnotetext{
${ }^{10}$ A.M. Best describes this variable as a company's "marketing type."

${ }^{11}$ In their seminal work on property rights theory, Grossman and Hart (1986) apply their model to the insurance industry. They predict that company firms (those using exclusive agents) will hold the majority of marketshare in LA. Their predictions align with the insurance industry structure in the early 1980s, when independent firms has only $12 \%$ marketshare in LA. These marketshares are the opposite of what we find in Texas using more recent data.
} 
and consider only complaints about LA sales. ${ }^{12}$ In total, we identify 5,406 accusations of sales misconduct leveled against 3,707 individuals present in our 2010 LA licensing data. In total, 1,962 LA sales complaints (approximately 36\% of the total) were found to be justified.

Figure 4 presents graphically the distribution of total and justified complaints per agent by agent type. There are several things to note in the figure: First, as predicted by the theory model presented in Section 1.2, exclusive agents face more total and more justified complaints than independent sellers - 1,133 of the justified complaints were against exclusive agents, while 829 justified complaints were against independent agents. One might wonder if exclusive agents accumulate more complaints as a result of a higher volume of business; however, this does not appear to be the case. As noted above and in Table 2, firms using exclusive agents actually have much lower total marketshare by premiums written, relative to independent firms. Firms with exclusive agents represent approximately $11 \%$ of the market and firms with independent agents represent the remaining $89 \%$. That is, exclusive agents are the subject of roughly $35 \%$ more complaints, yet they do only one-eighth of the business.

Second, complaints (justified or not) are rare events for both exclusive and independent agents. Only $2.75 \%$ of exclusive agents and $0.91 \%$ of independent agents have been the subject of any complaint filed with the TDI; only $1.44 \%$ of exclusive agents and $0.53 \%$ of independent agents have been named in a justified complaint.

Third, conditional on being the subject of any justified complaint, most agents receive only one complaint - $82 \%$ of exclusive agents and $84 \%$ of independent agents with any confirmed misconduct have faced only one complaint in the sample. These summary statistics support the notion that agents cannot easily build a reputation for ethical behavior in this context.

Figure 5 shows the distribution of complaints by the agents' experience for exclusive and independent agents, as measured by the years between when they were first licensed to sell LA products and when they received a justified complaint. We excluded agents with less than three years experience as of 2010, since their complaints may not yet have been processed by the TDI. The distributions indicate that exclusive and independent agents do not face justified complaints only in their first years of service; instead, relatively experienced agents are still subject to justified complaints, even after more than 20 years in the industry.

Figure 5 also suggests that exclusive agents receive more complaints later in their careers, relative to independent agents. A Kolmogorov-Smirnov test confirms that the distributions of complaints against exclusive and independent agents are not equal $(p<0.01)$.

While these figures are suggestive - complaints seems to vary systematically with agent

\footnotetext{
${ }^{12}$ We exclude complaints relating to property and casualty products, medicare supplements and employment insurance sales. We also drop complaints that were referred to other agencies for investigation.
} 
type and experience summary statistics do not capture other differences. We account for more factors in our next section of regression results, and we explore alternative explanations in Section 5.

\section{Results}

Are exclusive agents more likely to have been the subject of a justified complaint, relative to independent agents? ${ }^{13}$ To address this question, we estimate the following equation:

$$
\operatorname{Pr}\left(\text { Complaint }_{i}=1\right)=\frac{1}{1+e^{\square Q_{i}}}
$$

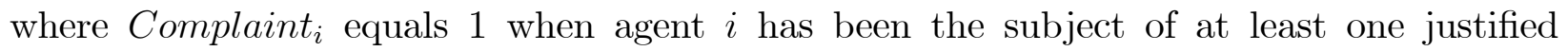
complaint and where

$$
Q_{i}=\alpha \text { Exclusive }_{i}+\beta X_{i}
$$

where Exclusive $_{i}$ equals 1 when agent $i$ is an exclusive agent $\left(\right.$ Exclusive $_{i}=0$ if the agent is independent) and matrix $X_{i}$ contains the agent-specific controls described below.

Complaints against insurance agents occur very infrequently in the data - as described in section 3.2, fewer than $2 \%$ of LA agents in Texas have been the subject of a justified complaint. Since typical econometric techniques, including logistic regressions, may underestimate the probability of rare events, coefficient and variance estimates are corrected using a rare-events correction suggested by King and Zeng (2001a, 2001b).

Although the main thrust of our analysis is concerned with differences between exclusive and independent agents (coefficient $\alpha$ ), our predictions also speak to the role of agent experience.

We include the following controls in $X_{i}$, summarized in Table 3 for exclusive and independent agents:

Years since first licensed: As a proxy for agent experience, we calculate the years since an agent was first licensed to sell insurance in Texas. If agents were licensed in other states prior to licensing by the TDI, we will underestimate their professional experience; if agents allowed their licenses to lapse in some interim periods, we will overestimate their experience. ${ }^{14}$ On average, exclusive agents have been licensed longer than independent agents $(p<0.01)$, holding licenses for roughly 10.5 years and 7 years, respectively.

\footnotetext{
${ }^{13}$ This question captures most misconduct - as shown in Figure 1, only $16 \%$ of LA sales agents receive multiple complaints.

${ }^{14}$ The date of licensing was not available for approximately $1.5 \%$ of LA agents. We exclude these agents from the analysis.
} 
Out-of-state agent: All agents who market insurance to consumers in Texas must be licensed by the TDI; however, they may be physically located in another state. We use the address on agents' licenses to determine residency and include a dummy variable to indicate when an agent resides outside of Texas. There are more independent agents with out-of-state business addresses, relative to exclusive agents $(p<0.01)$.

Professional designation: Insurance agents may seek certification from several professional organizations. In general, these organizations require members to complete course work, pass exams, and participate in continuing education. We matched agents to member lists for 11 designations. ${ }^{15}$ In our empirical analysis, we include a dummy variable indicating whether the agent holds any professional designation. Overall, very few sellers have these professional credentials. However, slightly more exclusive agents hold an accreditation, relative to independent agents $(p<0.01)$-roughly $2 \%$ versus $0.8 \%$, respectively.

Number of Licenses : While most agents are licensed to sell only one type of insurance, we include a dummy variable to indicate whether an agent is licensed to sell other products along with LA products (e.g. property and casualty insurance). Independent agents are more likely to specialize in LA products $(p<0.01)$ - approximately $72 \%$ of exclusive agents and $83 \%$ of independent agents sell only LA products.

Local population: Using a distance algorithm, we calculate the distance between the geographic centroid of all Texas ZIP codes and match ZIP codes to population data from the U.S. Census Bureau. We identify all ZIP codes within 25 miles of every agent's business address (for Texas residents) and aggregated the ZIP code populations. Unfortunately, we are not able to map non-resident agents to any specific geographic region of Texas. For residents, there is little difference between the average local populations faced by exclusive and independent agents.

\subsection{Exclusive vs. independent agents}

Table 4 reports estimation results from equation (1) with the rare events correction. To ease interpretation, we transform our estimated coefficients and report odds ratios. Each observation represents a unique agent.

Column 4.1 includes all agents in the data for whom information is available and controls for agents' experience, professional credentials, residency, and licensing. The estimates suggest that exclusive agents are more likely to have received a justified complaint than independent agents $(p<0.01)$. Even before adjusting for the very unequal marketshares of firms using exclusive and independent agents - recall that, in total, exclusive agents do

\footnotetext{
${ }^{15}$ The designations are: CFP, ChFC, CLU, CAP, CASL, CLF, FSS, LUTCF, MSFS, MSM, and REBC.
} 
nearly eight times less business than independent agents - the odds of an exclusive agent being the subject of a justified complaint are roughly $73 \%$ higher, relative to an independent agent.

In Column 4.2, we exclude agents with less than three years of experience as of 2010, since these inexperienced agents may be still in their training period, may be paid a guaranteed "training" salary, and may not yet be responsible for generating their own sales. Excluding these agents does little to change the coefficient of interest - the difference between exclusive and independent agents is large and statistically significant $(p<0.01)$.

Both local and out-of-state agents can be licensed to market insurance products in Texas. Column 4.3 includes only agents who reside in Texas. Again, the coefficient on the indicator for exclusive agents is statistically significant and similar in magnitude to the other specifications $(p<0.01)$.

Agents may differ in terms of their geography and, as a result, face different volumes of business. Although agent-level data on the volume or value of transaction are not available, we proxy for these measures using ZIP code-level U.S. Census population data. Results are reported in Column 4.4. This measure of business volume is statistically significant and very small in magnitude $(p<0.01)$. However, its inclusion has little effect on the coefficient of interest.

\subsection{Years of experience}

Across the specifications in Table 4, one additional year of agent experience is associated with a roughly 4 to 7 percentage points increase in the odds of receiving a complaint. Of course, agents with more experience have had more opportunities to receive a complaint. In this section, we present results suggesting that longevity alone cannot explain the estimated effect of experience.

In Table 5, we present results of a Tobit specification with a measure of misconduct normalized by agents' experience - complaints per licensed year - as the dependent variable. Column 5.1 excludes agents with less than three years of experience. In column 5.2, because we have only fifteen years of complaints data, we consider only agents with three to fifteen years of experience. In column 5.3, we include only Texas resident agents with licenses for three to fifteen years. Column 5.4 includes the measure of local population describe in the previous subsection.

Similar to the results in Table 4, exclusive agents are subject to more complaints per year of experience $(p<0.01)$. Complaints per year also increases with years of experience $(p<0.01)$. In terms of magnitude, without controlling for agents' marketshare, one addi- 
tional year of experience is associated with an additional 0.01 to 0.02 complaints per year of experience.

We expect our estimates to be a lower bound on the true effect of experience. The longer an agent has been in business, the greater the proportion of "bad apples" in his cohort that has been weeded out through disciplinary actions. Because we observe complaints only for agents licensed as of 2010, complaints against these "bad apples" are not included. As a result, our estimates of the effect of experience could be biased towards zero. Client attrition may also attenuate estimates of the effect of agent experience. ${ }^{16}$

\section{$5 \quad$ Alternative Explanations}

While our results are consistent with the simple model of price-taking experts presented in Section 1, several alternative hypotheses may be proposed to explain our findings. Specification, in this section, we consider the following alternatives: (1) agent sorting between firm types; (2) consumer heterogeneity; and (3) firms' "deep pockets" and reporting rates.

\subsection{Agent sorting}

One might ask: Do firms using exclusive agents systematically hire less honest agents? This seems unlikely given that these firms have established screening processes for their salespeople (e.g. applications, background checks, and interviews). In contrast, independent agents establish their own practices and are not subject to this initial screening. Moreover, dishonest exclusive agents who are fired are unlikely to gain employment at another firm using exclusive agents, but can readily move into independent sales. Thus, the pool of independent agents may include former exclusive agents who were terminated due to misconduct.

Do honest exclusive agents become independent operators after building up experience in the industry? If true, this could drive the difference in complaint rates between exclusive

\footnotetext{
${ }^{16}$ The following example illustrates this potential: Assume for now that there is no client attrition and an agent acquires ten clients per year. In ten years, a new agent has acquired a hundred clients. Suppose that the chance of receiving a complaint is $1 \%$ per client per year. This means that an agent with ten years of experience should (in expectation) receive one complaint. In an agent's twentieth year, he has two hundred clients and should expect two complaints. Thus, without attrition, complaints per year does not depend on experience. Now consider the role of client attrition. Over the past ten years, an agent with twenty years of experience has acquired the same number of clients as an agent with only ten years of experience. However, due to attrition, the number of clients that he retained from his first ten years is now less than the number of clients from the more recent decade. Thus, assuming that the chance of a complaint is still $1 \%$ per client per year, we would expect the ratio of complaints per year of the agent with twenty years of experience to be less than the ratio of the agent with ten years of experience. Thus, we underestimate the true effect of experience on complaints.
} 
and independent agents. In the data, this movement might lead to disparity between experience levels, with relatively young exclusive agents and relatively old independent experts. However, on average, exclusive agents have actually been licensed significantly longer than independent agents $(p<0.01)$.

Are out-of-state agents - individuals whose misconduct may be hard to detect because of distance driving the disparity between exclusive and independent agents' complaint rates? Empirical evidence suggest that this is not the case. There are significantly more outof-state agents acting as independent sellers rather than exclusive agents (Table $3 ; p<$ 0.01). Moreover, the regression presented in column 4.3 excludes out-of-state agents and still estimates a large and statistically significant difference between agent types $(p<0.01)$.

One might also wonder if bad agents are being detected and fired by the firms using exclusive agents. Although our data do not allow us to observe this directly, this sorting would work against our predicted effect. That is, we would expect to observe higher complaint rates for independent agents if these firms included former "bad" company agents.

Agents might also sort geographically — one might worry that the differences in exclusive and independent agents' behavior results from differences in the local competitive landscape. An average ZIP code in Texas contains 31 independent agents (standard deviation of 52) and 19 exclusive agents (standard deviation of 34), and approximately $84 \%$ of ZIP codes in Texas contain at least one of each type of agent. Given that both agents and customers are likely to transact across ZIP codes, we constructed another measure of local competition. Using a distance algorithm, we calculated the distance between the geographic centroid of all Texas ZIP codes. We identified all ZIP codes within 25-miles of an agent's business address and counted the total number of agents within that radius. Overall, exclusive and independent agents face similar numbers and types of competitors: for both independent and exclusive agents, approximately $38 \%$ of agents within a 25 -mile radius are exclusive and $62 \%$ are independent.

\subsection{Customer heterogeneity}

We find little evidence to support agent sorting as the source of the disparity between the misconduct of exclusive and independent agents. However, one might be concerned that customer heterogeneity is driving the effect. That is, one might worry that the matching of particularly savvy customers to independent agents (or vice versa) could be leading to the observed misconduct rates. In the following section, we consider both theoretical and empirical arguments relating to customer sorting.

To consider the impact of savvy consumers on the market equilibrium, we introduce 
"connoisseur" consumers into the model and, for the moment, hold the agents' types fixed. Connoisseurs are defined as consumers who are perfectly informed about the appropriateness of the recommended product and, therefore, only and always buy from an expert who recommends $R$. We assume that experts cannot distinguish a connoisseur from a regular customer - otherwise, the expert would always suggests $R$ to those consumers, and regular consumers would be unaffected. Note that adding connoisseurs is equivalent to introducing some exogenous probability that a consumer knows the appropriate product for herself.

Suppose that there is a mass $\alpha$ of connoisseurs in the market. Now, experts enjoy a higher expected payoff for suggesting $R$ and lower expected payoff for suggesting $W$. Consider the probability of misconduct in a market with connoisseurs:

$\left.\left.\left.\operatorname{Pr}\left[(1 \square \alpha) b \pi^{W} \square k\right) \square \alpha k \geq(1 \square \alpha) b \pi^{R}+\alpha \pi^{R}\right]=F^{\square}(1 \square \alpha) b^{\square} \pi^{W} \square \pi^{R}\right) \square \alpha \pi^{R}\right) \equiv s_{\alpha}(b)$

As expected, holding the buy rate fixed, misconduct is decreasing in $\alpha$.

Now, the buy rate for non-connoisseur consumers is

$$
\left.\operatorname{Pr} s V^{W}+(1 \square s) V^{R} \geq 0\right)=1 \square G\left(\frac{s}{(1 \square s)}\right) \equiv b_{\alpha}(s)
$$

Figure 3 plots the market-wide misconduct and buy rate when we introduce some mass $\alpha$ of connoisseur consumers, and we compare this market against one with no such customers (i.e., when $\alpha=0$ ). In this setting, it is the misconduct curve - the inverse of the market-wide supply $s_{\alpha}^{*}(b)$ - that changes. Intuitively, with the introduction of connoisseur consumers, the expected payoff to misconduct is reduced in two ways: first, experts face a greater chance of being caught when suggesting $W$; and, second, experts are more likely to be rewarded with a purchase when they suggest $R$. That is, the presence of connoisseur consumers provides both a stick and carrot to entice more experts towards appropriate recommendations. Graphically, the line representing the inverse of market-wide level of misconduct in the presence of connoisseur consumers $s_{\alpha>0}(b)^{\square 1}$ ) lies above the misconduct curve when connoisseurs are not in the market $s_{\alpha=0}(b)^{\square 1}$ ). As can be seen in Figure 3, the new equilibrium with connoisseur consumers is characterized by less overall misconduct and a higher market-wide buy rate. This yields the following proposition:

Proposition 4 Increasing the mass of connoisseur consumers $\alpha$ decreases misconduct $s_{\alpha}^{*}(b)$.

Proof. See Appendix.

Unfortunately, data on individual agents' clientele is not available, as it is proprietary information. However, we can use location information in the licensing data and gather demographic information on the populations near agents' business addresses. 
For this empirical exercise, we consider the proportion of the local population that is employed in the financial sector; we assume that employment in the finance, banking or insurance industry is correlated with knowledge of insurance needs. We used the distance algorithm described above and matched ZIP codes to 2010 County Business Pattern data from the U.S. Census Bureau. ${ }^{17}$ After identifying all ZIP codes within 25-miles of an agent's business address, we aggregated the employment statistics. ${ }^{18}$

Note that the sample size for this analysis is necessarily smaller than for many of the previous regressions, since we cannot include potential client employment statistics for agents without a Texas business address. However, the regression results in Table 6 can be compared to those in Table 4, columns 4.3 and 4.4.

Columns 6.1 to 6.4 presents results from the regression on an indicator of any justified complaints. Columns 6.1 and 6.3 include the measure of informedness and columns 6.2 and 6.4 add a measure of the local population. Across these four columns, the coefficients on employment in finance are positive and vary in terms of magnitude and statistical significance. In the columns of Table 6, the inclusion of the employment measures has little impact on the main coefficients of interest - exclusive agents are the subject of more justified complaints than independent agents. We note that, holding fixed the level of misconduct, if more savvy customers are more likely to report a complaint, then observed complaint rates should be greater for experts working in more finance-oriented areas.

\subsection{Deep pockets and reporting rates}

One might be concerned that customers of branded companies are more likely to file a complaint due to the perceived "deep pockets" of these large firms. In this section, we explore this possibility and argue that it cannot fully rationalize the observed differences between the complaints against exclusive and independent agents.

If the cost of filing is very low, then almost every discovered abuse should be reportedindeed, even customers who fail to detect any misconduct should contact the regulator for a costless (to them) review of the transaction. ${ }^{19}$ However, if there exists some material cost of filing a complaint, then customers of exclusive experts will report suspected misconduct more often if they expect a higher payoff from a successful complaint, relative to the payoff from

\footnotetext{
${ }^{17}$ We also consider consumers' education levels using the percentage of the nearby population with a college education. Results are similar.

${ }^{18}$ We multiplied the mid-point of the employment size class with the number of establishments in that class.

${ }^{19}$ Empirically, the reporting cost is expected to be quite low, but not zero. Customers can go online to the TDI website and fill out a form in a matter of minutes. Insurance policies also must list contact information for filing a complaint.
} 
complaining about an independent seller. In this case, even if exclusive and independent experts are equally ethical, exclusive experts will face more complaints.

To illustrate, consider a mass of experts indexed by $g$, where $g \in[0,1]$. A customer reports an expert when she has an expected positive return from doing so. This happens when the expert is sufficiently likely to be guilty and thus convicted of misconduct. Denote $g^{*}$ such that for all $g \geq g^{*}$, the customer reports suspected misconduct; hence, the market-wide report rate is $1 \square g^{*}$.

Suppose that, for any given $g$, the probability of misconduct is $\operatorname{Pr}$ (guilty) $\equiv g^{a}$, where $a \in(0, \infty){ }^{20}$ The expected market-wide conviction rate for all reported experts is

$$
\operatorname{Pr}(\text { conviction } \mid \text { reported })=\frac{\operatorname{Pr}(\text { conviction } \cap \text { reported })}{\operatorname{Pr}(\text { reported })}=\frac{\int_{g^{*}}^{1} g^{a} d g}{1 \square g^{*}} .
$$

For exclusive agents in our data, the empirical complaint rate is 0.04 and the conditional conviction rate is 0.38 . Hence,

$$
\operatorname{Pr}(\text { conviction } \mid \text { reported, exclusive })=\frac{\int_{0.96}^{1} g^{a} d g}{0.04}=0.38
$$

and, therefore,

$$
a \simeq 59.14
$$

For independent agents in our data, the complaint rate is approximately 0.01. Now, assume for a moment that both exclusive and independent experts have the same unconditional guilty rate - that is, assume that it is differences in the reporting rates (and not underlying misconduct) that drives the observed disparity in complaints. Under this assumption, the conditional conviction rate for independent agents would be

$$
\operatorname{Pr}(\text { conviction } \mid \text { reported, independent })=\frac{\int_{0.99}^{1} g^{59.14} d g}{0.01}=0.75
$$

Recall that the observed conditional conviction rate for independent experts is 0.40 under the assumption of similar guilt, the simulated conditional conviction rate is almost

\footnotetext{
${ }^{20}$ Note that this parameter space allows us to consider conviction rates under which, in the limit, no agent, some agents, or every agent is guilty.
} 
twice the actual rate. Hence, it is unlikely that independent experts are equally guilty, but subject to less reporting. Moreover, the conditional conviction rates are in fact quite similar: 0.38 for exclusive vs. 0.40 for independent experts. If anything, the conditional conviction rates should be much higher for independent experts since they may be reported only in the most extreme cases.

There is another dimension to "deep pockets" that also works against the argument that the empirical finding is being driven by reporting rates. Firms with extensive resources might be particularly unwilling to concede to accusations of misconduct or settle a lawsuit - indeed, their large coffers may serve as evidence that they can credibly outlast their accusers in any legal fight.

Finally, according to the TDI, insurance companies may work directly with unhappy customers to resolve their issues and discourage them from taking the complaints to the regulator. ${ }^{21}$ Insurance companies using exclusive agents have a structure that is particularly well-suited for diverting these complaints - in general, branch and regional managers, as well as telephone customer service agents, can adjust policies or payments in response to customers' claims. In contrast, customers of independent experts may have little recourse before contacting the regulator. As a result, in the data, we might expect observed complaint rates for exclusive agents to represent a lower bound on actual misconduct.

\section{Conclusion}

In this paper, we explore how the level of misconduct in credence good markets with pricetaking experts varies across organizational forms. We propose a market-wide model that shows that price-taking experts extract surplus based on the value of their firm's brand and services' or their own skill through increased malfeasance. We find empirical evidence that these markets operate differently than in standard asymmetric information problem settings. In particular, rather than experts with strong reputations behaving more ethically, exclusive experts working for large branded firms are actually more likely to be the subject of a complaint, relative to independent experts. Similarly, experts who survive over time and become more skilled exhibit the greatest levels of misconduct.

Our research relates to the current discussion of the Dodd-Frank Wall Street Reform and Consumer Protection Act of 2010. Currently, regulations distinguish between two types of investment experts and hold them to different standards of conduct. Registered investment advisors are held to a "fiduciary standard" that requires them to disclose all conflicts and provide the client with the most appropriate recommendation. In contrast, investment bro-

\footnotetext{
${ }^{21}$ We learned this through telephone conversations with staff at the TDI.
} 
kers are held to a lower "suitability standard" that requires them to provide the client with a recommendation that is consistent with their needs, but not necessarily the most appropriate. According to SEC research, many customers are unaware of the differing standards and believe that both advisors operate under the higher standard of conduct (U.S. Securities and Exchange Commission 2011).

Our research about the relationship between misconduct and organizational form can inform the debate. Brokers often work for large branded companies, whereas registered investment advisors are often independent. We find that experts working in large branded firms are already likely to extract additional surplus through misconduct. Thus, holding these brokers to a lower standard may exacerbate consumer harm.

In the same report, the SEC suggests that investor education is needed. Our model highlights the potential benefits of increased consumer awareness - the presence of many informed customers can reduce market-wide misconduct. Finally, if more experienced advisors are more likely to take advantage of customers, the standards of conduct could vary across experience levels; however, to our knowledge, this aspect of the professional standards has not yet been explicitly discussed by the regulator. 


\section{References}

[1] Alger, Ingela and Francois Salanie. 2006. "A Theory of Fraud and Overtreatment in Experts Markets." Journal of Economics \& Management Strategy, 15(5): 853-881.

[2] A.M. Best Company. 2011. "Best's Key Rating Guide: Life/Health United State \& Canada." Oldwick, New Jersey.

[3] Anagol, Santosh, Shawn Cole, and Shayak Sarkar. 2012. "Understanding the Incentives of Commissions Motivated Agents: Theory and Evidence from the Indian Life Insurance Market." Working paper.

[4] Carson, James, Randy Dumm, and Robert Hoyt. 2007. "Incentive Compensation and the Use of Contingent Commissions: The Case of Smaller Distribution Channel Members." The Journal of Insurance Regulation, 25(4): 53-67.

[5] Cobb-Walgren, Cathy J., Cynthia A. Ruble and Naveen Donthu. 1995. "Brand Equity, Brand Preference, and Purchase Intent." Journal of Advertising, 24(3): 25-40.

[6] Cooper, Robert, and Gary Frank. 2005. "The Highly Troubled Ethical Environment of the Life Insurance Industry: Has It Changed Significantly from the Last Decade and If so, Why?" Journal of Business Ethics, 58(1): 149-157.

[7] Darby, Michael and Edi Karni. 1973. "Free Competition and the Optimal Amount of Fraud." Journal of Law and Economics, 16(1): 67-88.

[8] Dulleck, Uwe and Rudolf Kerschbamer. 2006. "On Doctors, Mechanics, and Computer Specialists: The Economics of Credence Goods." Journal of Economic Literature, 47: $5-42$.

[9] Emons, Winand. 1997. "Credence Goods and Fraudulent Experts." The RAND Journal of Economics, 28(1) Spring: 107-119.

[10] Feddersen, Timothy and Thomas Gilligan. 2001 "Saints and Markets: Activists and the Supply of Credence Goods." Journal of Economics \&3 Management Strategy, 10(1) Spring: 149-171.

[11] Fong, Yuk-fai. 2005. "When Do Experts Cheat and Whom Do They Target?" The RAND Journal of Economics, 36(1): 113-130.

[12] Gennaioli, Nicola, Andrei Shleifer, and Robert W. Vishny. 2012. "Money Doctors." NBER Working Paper No. 18174. 
[13] Grossman, Sanford, and Oliver Hart. 1986. "The Costs and Benefits of Ownership: A Theory of Vertical and Lateral Integration." Journal of Political Economy, 94(4) August: 691-719.

[14] Hubbard, Thomas N. 1998. "An Empirical Examination of Moral Hazard in the Vehicle Inspection Market." RAND Journal of Economics, 29(2) Summer: 406-426.

[15] Hubbard, Thomas N. 2002. "How Do Consumers Motivate Experts? Reputational Incentives in an Auto Repair Market." Journal of Law and Economics, 45 October: 437468.

[16] Inderst, Roman and Marco Ottaviani. 2009. "Misselling through Agents." American Economic Review, 99(3): 883-908.

[17] Inderst, Roman and Marco Ottaviani. 2012a. "How (not) to pay for advice: A framework." Journal of Financial Economics, 105 August (2): 393-411.

[18] Inderst, Roman and Marco Ottaviani. 2012b. "Competition through Commissions and Kickbacks." American Economic Review, 102(2) April: 780-809.

[19] Keller, Kevin and Donald Lehmann. 2006. "Brands and Branding: Research Findings and Future Priorities." Marketing Science, 25(6): 740-759.

[20] King, Gary and Langche Zeng. 2001a. "Logistic Regression in Rare Events Data." Political Analysis, 9(2): 137-163.

[21] King, Gary and Langche Zeng. 2001b. "Explaining Rare Events in International Relations." International Organization, 55(3) August: 693-715.

[22] Levitt, Steven D. and Chad Syverson. 2008 "Market Distortions When Agents Are Better Informed: The Value of Information in Real Estate Transactions." Review of Economics and Statistics, 90(4): 599-611.

[23] Lightle, John. 2009. "The Paternalistic Bias of Expert Advice." Florida State University working paper.

[24] Mailath, George J., and Larry Samuelson. 2001. "Who Wants a Good Reputation?" Review of Economic Studies, 68 (2) April: 415-441.

[25] Mullainathan, Sendhil, Markus Noeth, and Antoinette Schoar. 2012. "The Market for Financial Advice: An Audit Study." NBER Working Paper No. 17929. 
[26] Pessendorfer, Wolfgang and Asher Wolinsky. 2003. "Second Opinions and Price Competition: Inefficiency in the Market for Expert Advice." The Review of Economic Studies, 70(2): 417-437.

[27] Pitchik, Carolyn and Andrew Schotter. 1987. "Honesty in a Model of Strategic Information Transmission." American Economic Review, 77(5): 1032-1036.

[28] Sulzle, Kai and Achim Wambach. 2005. "Insurance in a Market for Credence Goods." The Journal of Risk and Insurance, 72(1): 159-176.

[29] Taylor, Curtis R. 1995. "The Economics of Breakdowns, Checkups, and Cures" Journal of Political Economy, 103(1) February: 53-74.

[30] U.S. Securities and Exchange Commission. 2011. "Study on Investment Advisers and Broker-Dealers." Available online as of 20 Sept. 2013: http://www.sec.gov/news/studies/2011/913studyfinal.pdf 


\title{
7 Appendix
}

\subsection{Insurance companies using exclusive agents in Texas}

\author{
Allstate Life Insurance Company \\ American General Life And Accident Insurance Company \\ American National Insurance Company \\ Axa Equitable Life Insurance Company \\ Baltimore Life Insurance Company \\ Beneficial Life Insurance Company \\ Farmers Insurance Exchange \\ First Acceptance Insurance Company \\ Guideone Mutual Insurance Company \\ Kansas City Life Insurance Company \\ Liberty Mutual Insurance Company \\ Metropolitan Life Insurance Company \\ Modern Woodmen Of America \\ Monumental Life Insurance Company \\ MONY Life Insurance Company Of America \\ Mutual Of Omaha Insurance Company \\ National Life Insurance Company \\ Nationwide Mutual Insurance Company \\ New York Life Insurance Company \\ Northwestern Mutual Life Insurance Company \\ Penn Mutual Life Insurance Company \\ Pennsylvania Life Insurance Company \\ Physicians Life Insurance Company \\ Provident American Life \& Health Insurance Company \\ State Farm Life Insurance Company \\ Thrivent Financial For Lutherans \\ Western And Southern Life Insurance Company
}

A list of insurance companies licensed in Texas that use independent agents is available upon request. 


\subsection{Proofs}

Proposition 1: Exclusive experts are more likely to engage in misconduct than independent experts: $s_{E}^{*}\left(b^{*}\right)>s_{I}^{*}\left(b^{*}\right)$.

Proof. This proof formalizes the results from Figure 1. Recall that $F(\cdot)$ is the same for both firm types and that, since $\eta>1, G_{E}(\cdot)<G_{I}(\cdot)$ for all $s \in(0,1)$.

For any expert type, note that $b(s)$ is strictly decreasing in $s$; in a market without misconduct, customers always buy $(b(0)=1)$; and in a market in which experts always engage in misconduct, customers never buy $(b(1)=0)$.

Define the inverse of the misconduct function: $q(\cdot) \equiv s(b)^{\square 1}$. Since $s(b)$ is strictly increasing and continuous, so too is $q(\cdot)$. In addition, if customers never buy, then experts never engage in misconduct $(q(0)=0)$ and if customers always buy, then experts engage in at least some misconduct $(q(1)>0)$.

A unique, interior equilibrium follows from these three features: (1) continuity of $b(\cdot)$ and $q(\cdot) ;(2)$ the ordering of end point values, $b(0)=1>q(0)=0$ and $b(1)=0<q(1)$; and (3) strict monotonicity of $b(\cdot)$ and $q(\cdot)$.

To compare organizational forms, recall that $G_{E}(\cdot)<G_{I}(\cdot)$ for all interior values of $s$. That is, for all interior points and for a given level of misconduct, exclusive experts face a higher buy rate than independent experts $\left(b_{E}^{*}>b_{I}^{*}\right)$, which implies that the misconduct rate of exclusive experts is higher than that of independent experts $\left(s_{E}^{*}\left(b^{*}\right)>s_{I}^{*}\left(b^{*}\right)\right)$ because $s(b)$ is strictly increasing.

Proposition 2: More error-prone experts are less likely to engage in misconduct. That $i s, s^{*}$ is decreasing in the error rate $h$.

Proof. This proof formalizes the results from Figure 2. First note that $G_{h}(\cdot)$ is increasing in the error rate $h$. Holding the misconduct rate $s$ constant, the buy rate $b_{h}(s)$ is decreasing in $h$ for $s<1$.

The misconduct rate is unaffected by the introduction of error-prone experts since

$$
\left.\left.\left.\left.\operatorname{Pr} b \pi^{W} \square k \geq(1 \square h) b \pi^{R}+h \quad b \pi^{W} \square k\right)\right)=F^{\square} \quad b \quad \pi^{W} \square \pi^{R}\right)\right) \equiv s_{h}(b)=s(b)
$$

Following arguments provided in Proposition (1), equilibrium misconduct $s_{h}^{*}\left(b^{*}\right)$ is decreasing in the error rate $h$.

Proposition 3: Increasing the mass of connoisseur consumers $\alpha$ decreases misconduct $s_{\alpha}^{*}(b)$.

Proof. This proof formalizes the results from Figure 3. Recall from the text that $\alpha$ describes the mass of connoisseur consumers in the market. Define the inverse of the market-wide misconduct function $q_{\alpha}(\cdot) \equiv s_{\alpha}(b)^{\square 1}$, and note that $q_{\alpha}(\cdot)$ is strictly increasing and continuous in $s$.

Also note the following: the buy rate in the presence of connoisseur consumers $\left(b_{\alpha}(s)\right)$ is strictly decreasing in $s$; if experts never engage in misconduct, then customers always buy $\left(b_{\alpha}(0)=1\right)$; and if experts always engage in misconduct, then customers never buy $\left(b_{\alpha}(1)=0\right)$. 
Consider the condition under which experts would not engage in misconduct: $s_{\alpha}(b)=0$ requires that $\left.(1 \square \alpha) b \pi^{W} \square \pi^{R}\right) \square \alpha \pi^{R}=0$, since $F(0)=0$. This implies that $b>0$ and, therefore, when the market includes some connoisseur consumers, even some positive buy rate yields a market with no misconduct.

The inverse of the market-wide misconduct function with connoisseur consumers lies everywhere to the left of the original misconduct function $q_{\alpha>0}(0)>q_{\alpha=0}(0)$ for all values of $b$. However, conditional on a given level of misconduct, the buy rate is unchanged by the presence of connoisseurs $\left(b_{\alpha>0}(s)=b_{\alpha=0}(s)\right)$. Hence, in equilibrium, the market-wide misconduct declines with the inclusion of more connoisseur consumers. 